\title{
Transdermal Delivery of Ketorolac
}

\author{
Chandra AMRISH ${ }^{*, a}$ and Sharma Pramod $\operatorname{KUMAR}^{b}$ \\ anstitute of Pharmacy, Bundelkhand University, Kanpur Road, Jhansi 284128 (U.P.), India, and ${ }^{b} R . V$. \\ Northland Institute, $18 \mathrm{Km}$ Gaziabad-Bulandshahar Road, G.T. Road (Greater Noida Phase II), \\ Dadri, Gautam Budh Nagar 203207 (U.P.), India
}

(Received June 30, 2008; Accepted December 4, 2008)

\begin{abstract}
A reservoir type transdermal patch for delivery of ketorolac, a potent analgesic agent was studied. The low permeability of skin is the rate-limiting step for delivery of most of the drugs. Studies were carried out to investigate the effect of permeation enhancers on the in vitro permeation of ketorolac across rat skin. The reservoir type transdermal patch was fabricated and the core was filled with gel system of a non ionic polymer HPMC (hydroxypropyl methyl cellulose) formulated in PBS (phosphate buffer saline) solution of pH of 5.4 along with isopropyl alcohol at $25 \% \mathrm{w} / \mathrm{w}$ concentration. Various permeation enhancers' viz. dimethyl sulphoxide, d-limonene, eucalyptus oil and transcutol (diethylene glycol monoethyl ether) were incorporated into the gel system. Permeation enhancement of ketorolac with different enhancers followed the order eucalyptus oil $>$ transcutol $>$ DMSO $>$ d-limonene. Cyclic terpene containing eucalyptus oil was found to be the most promising chemical permeation enhancer for transdermal delivery of ketorolac. The increase in concentration of eucalyptus oil further enhanced drug permeation with maximum flux being achieved at $10 \% \mathrm{w} / \mathrm{w}$ of $66.38 \mu \mathrm{g} / \mathrm{cm}^{2} / \mathrm{h}$. Further enhancement of permeation rate of ketorolac across skin was attained by application of abrading gel containing crushed apricot seed onto the skin. There was 5.16 times enhancement and flux of $93.10 \mu \mathrm{g} / \mathrm{cm}^{2} / \mathrm{h}$ was attained. A reservoir type transdermal patch for delivery of ketorolac thus appears to be feasible of delivering ketorolac across skin.
\end{abstract}

Key words_- ketorolac; skin; penetration enhancer; pretreatment; abrasive

\section{INTRODUCTION}

Ketorolac $(( \pm)$-5-benzoyl-2,3-dihydro-1H-pyrrolizine-1-carboxylic acid, 2-amino-2- ( hydroxy methyl) -1,3-propanediol; Mol. wt. $376.4 \mathrm{~g} / \mathrm{mol}$ ) is a prostaglandin synthetase inhibitor, a nonsteroidal anti-inflammatory drug with potent analgesic and moderate anti-inflammatory activities. ${ }^{1)}$ Ketorolac has been studied clinically and its efficacy and safety as an analgesic in cancer and postoperative pain has been established. Administered as injectable and oral formulations, it has shown high analgesic potency almost equivalent to that of morphine. ${ }^{2)}$ Unlike narcotic analgesics, ketorolac does not alter gastric motility or adversely affect respiration, nor is it associated with addiction potential as in case of narcotic analgesics; therefore, ketorolac is a relatively more favorable therapeutic agent for the management of moderate to severe pain. ${ }^{3)}$

Thus developing an alternative dosage form that is easy to administer; is painless; non invasive; easy to comply and avoids first pass metabolism, is worth-

\footnotetext{
*e-mail: amrish_chandra@yahoo.com
}

while. The transdermal route encompasses all the above advantages.

Despite these advantages, only a limited number of drugs can be administered percutaneously, due to low skin permeability of most drugs across the skin. The penetration through stratum corneum is the ratelimiting step for delivery of most of the drugs. To overcome this problem, vehicles, ${ }^{4)}$ penetration enhancers, ${ }^{5)}$ ultra sound ${ }^{6}$ ) and electro-transport ${ }^{7)}$ facilitated transdermal systems have been attempted in the development of a transdermal delivery system of ketorolac. Prodrug approach has also been investigated for enhanced dermal delivery. ${ }^{8,9)}$ However, the most widely used technique involves use of chemical penetration enhancers or solvents that modify the thermodynamic activity.

In the present study, we therefore investigate the effects of penetration enhancers on the in vitro permeation of ketorolac from hyrogel gel formulation across rat abdominal skin to examine the feasibility of developing a transdermal system.

\section{EXPERIMENTAL}

Materials Ketorolac was obtained as a gift sam- 
ple from Ranbaxy Laboratories, Devas, India. Hydroxy propyl methylcellulose, HPMC (Methocel ${ }^{\circledR} \mathrm{K}_{15}$ M) was gifted by Colorcon Asia Pvt. Ltd., Goa, Isopropyl Alcohol (IPA), dimethyl sulphoxide (DMSO) and Eucalyptus oil were purchased from Central Drug House, New Delhi and comprised 80-85 $\% \mathrm{w} / \mathrm{w}$ cineol. d-limonene was obtained from Hi Media Labs, Mumbai. Transcutol ${ }^{\circledR} \mathrm{P}$ (diethylene glycol monoethyl ether) was obtained from Gattefosse, France through Colorcon Asia Pvt. Ltd., Goa. Commercially available adhesive tape was procured from 3M (TM) Milipore (TM) tape (1530-3) was used. The adhesive used was Acrylate (25-35\% w/w) and EVA copolymer $(0.5-2 \% \mathrm{w} / \mathrm{w})$ and the moisture vapor transmission rate was $4200 \mathrm{~g} / \mathrm{m}^{2} / 24 \mathrm{~h}$. Other chemical and reagents used were of analytical grade. The experimental protocol was approved by the institutional animal ethical committee, Institute of Pharmacy, Bundelkhand University, Jhansi. The reported experiments were carried out in accordance with the guidelines of the committee for the purpose of control and supervision of experiments on animals (CPCSEA), constituted under the provision of Section 15 of the Prevention of Cruelty to Animals Act, 1960 of the Indian constitution.

Preparation of Ketorolac Gel System and Fabrication of Reservoir Type Patch Ketorolac gel system was prepared in PBS (phosphate buffer saline) solution by dissolving ketorolac and adding HPMC (hydroxyl propyl methylcellulose) with continuous stirring so as to uniformly disperse the polymer. Permeation enhancers were mixed with the vehicle before adding the polymer. The gel was kept overnight at ambient temperature in a tightly closed container to allow uniform gelling (cold dispersion method).

Transdermal patches (reservoir type) of ketorolac were fabricated by filling ketorolac gel preparation $(0.25 \mathrm{~g}$ per cm sq.) within a shallow compartment made of a hollow ring shaped device and drug impermeable backing membrane (laminated aluminum foil). A micro porous adhesive tape of a larger area was stuck onto the impermeable backing membrane to bring the transdermal patch in intimate contact with the skin. The device was closed by a release liner on the open side (Fig. 1).

Preparation and Method of Application of Abrasive Gel The abrasive gel was prepared by heating distilled water to $80^{\circ} \mathrm{C}$ and adding to it crushed apricot seed $(5 \% \mathrm{w} / \mathrm{w})$ (Prunus armeniaca). The

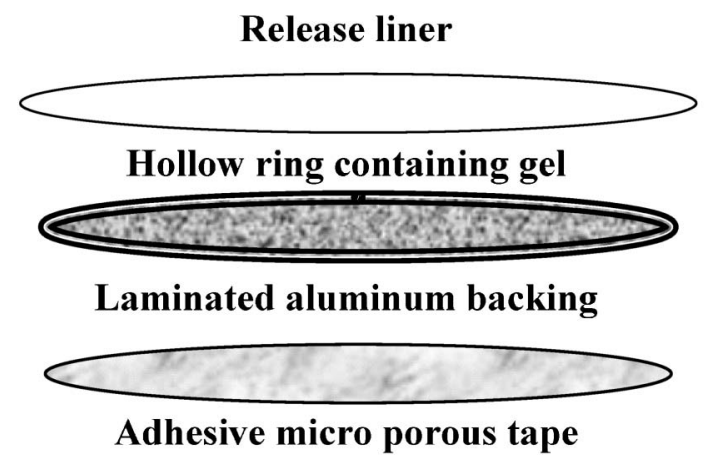

Fig. 1. Design of Fabricated Reservoir Type Patch for Transdermal Administration of Ketorolac

size of crushed pieces ranged between 354 and 251 $\mu \mathrm{m}$. The polymer HPMC $(2 \% \mathrm{w} / \mathrm{w})$ was then added slowly and allowed to disperse uniformly (hot dispersion method). It was then cooled to form viscous gel into which was entrapped crushed apricot shell pieces.

One g of the gel was topically applied with the help of index finger on the depilated site before application of formulation and was gently massaged onto the skin for a period of two minutes and pressure ranging between $30-50 \mathrm{~g} / \mathrm{cm}^{2}$. The crushed apricot pieces were dusted off with soft cloth.

In Vitro Skin Permeation Studies The abdominal skin of Sprague-Dawley rat was clamped between the donor and the receptor chamber with the stratum corneum surface facing the receptor compartment of modified Keshary Chien diffusion cell after removing the hair with a clipper. The effective diffusion area of the cell was $2.0 \mathrm{~cm}^{2}$ and had a receptor volume of 11 $\mathrm{ml}$. The receptor chamber was filled with freshly prepared PBS (phosphate buffer saline) solution pH 7.4. The diffusion bath was maintained at $37 \pm 1^{\circ} \mathrm{C}$ and the solution in the receptor chambers was stirred continuously with the help of magnetic bead. Ketorolac gel $(0.5 \mathrm{~g})$ was gently placed in the donor chamber and spread evenly on the rat abdominal skin. The donor compartment was covered with Parafilm $\mathrm{M}^{\circledR}$ to prevent evaporative loss. One $\mathrm{ml}$ of the solution in the acceptor chamber was removed for drug content determination and replaced immediately with an equal volume of fresh PBS solution pH 7.4. Drug concentration was determined UV spectrophotometrically.

Analysis of In Vitro Drug Release Study Samples Samples withdrawn were filtered through What- 
mann filter paper No. 42 and diluted whenever necessary. The samples were analyzed spectrophotometrically at $324 \mathrm{~nm}$. The concentration of drug was determined from the regression equation generated from the calibration curve, $y=0.0285 x+0.0012, R^{2}=$ 0.999 .

Effect of Permeation Enhancers Ketorolac gel system consisted of $2 \% \mathrm{w} / \mathrm{w}$ ketorolac and $2 \% \mathrm{w} / \mathrm{w}$ HPMC (hydroxyl propyl methylcellulose) in PBS solution at $\mathrm{pH}$ of 5.4 along with IPA (isopropyl alcohol) at $25 \% \mathrm{w} / \mathrm{w}$ and permeation enhancers. The gel system for the reservoir compartment of the transdermal patch was prepared by cold dispersion method. Various enhancers' viz. DMSO (dimethy sulfoxides), eucalyptus oil, d-limonene and transcutol (diethylene glycol monoethyl ether) were added at $5 \% \mathrm{w} / \mathrm{w}$ concentration. The concentration of the screened enhancer was further optimized at 7.5 and $10 \% \mathrm{w} / \mathrm{w}$.

Skin Irritation Studies Transdermal patch of ketorolac gel was applied onto the dorsal skin of Wistar rats $(220-250 \mathrm{~g})$ which was shaved $24 \mathrm{~h}$ prior to study. The site of application was occluded with gauze and covered with non-sensitizing adhesive microporous tape. After $24 \mathrm{~h}$, the gel was removed and the score of erythema was determined by Drazie test ${ }^{10)}$ as follows: 0- no eryhtema; 1- very slight erythema (barely perceptible); 2 - well-defined erythema; 3- moderate to severe eryhtema and 4- severe erythema (beet redness) to slight eschar formation (injuries in depth).

Carrageenan Induced Paw Edema The anti-inflammatory efficacy was evaluated by carrageenan induced paw inflammation in Wistar rat (approx. 220$250 \mathrm{~g}$ ). The rats were assigned to treatment groups so that each group was weight balanced. Ketorolac was administered via oral $(2 \mathrm{mg} / \mathrm{kg})$ and transdermal route $1 \mathrm{~h}$ before carrageenan injection. The transdermal patch was securely adhered over the depilated dorsal abdominal skin $\left(9 \mathrm{~cm}^{2}\right)$. The rats received intraplantar injection of $50 \mu \mathrm{l}$ of $0.5 \% \mathrm{w} / \mathrm{v}$ carrageenan suspension into the left hind paw subcutaneously by inserting the needle into the central part of the paw. The paw volume was measured and compared to with that found in animals treated with carrageenan alone. The right hind paw which served as control was treated with physiological saline solution without carrageenan. ${ }^{11}$ The inflammatory response was determined by measuring the changes in paw volumes with a screw gauge (Mitutoyo, Kanagawa, Japan) at 0, 2,
4, 6, 8 and $10 \mathrm{~h}$ after the carrageenan injection.

The degree of paw swelling was calculated as:

$$
\text { Swelling }(\%)=\frac{V t-V}{V} \times 100
$$

where, $V t$ is the volume of the carrageenan-treated paw, $V$ is that of the non-treated paw.

$$
\text { Inibition }(\%)=\frac{S c-S t}{S c} \times 100
$$

where, $S c$ is the swelling of the control paw, $S t$ is that of the test formulation treated paw. The AUC (area under the curve) was determined by trapezoidal method.

Acetic Acid Induced Writhing Effect Ketorolac was administered via oral $(2 \mathrm{mg} / \mathrm{kg})$ and transdermal route $1 \mathrm{~h}$ before administration of writhing agent. The transdermal patch was securely adhered over the depilated dorsal abdominal skin $\left(9 \mathrm{~cm}^{2}\right)$. The rats received intra peritoneally (i.p.) acetic acid $(20 \mathrm{mg} /$ $\mathrm{kg}, 2 \mathrm{ml} / \mathrm{kg}$ ) in deionized water. The number of writhes (i.e., abdominal constriction followed by dorsiflexion and extension) occurring during a $15 \mathrm{~min}$ period beginning and $15 \mathrm{~min}$ after acetic acid administration, was measured. The results are expressed as percentage inhibition in writhes.

Histological Studies Transdermal patch formulations were applied for $24 \mathrm{~h}$ on the dorsal surface of excised rat skin mounted on the diffusion cell. The transdermal patch was removed and the skin was wiped off with tissue paper, the skins were fixed in 10 $\% \mathrm{v} / \mathrm{v}$ formalin solution in saline for at least $72 \mathrm{~h}$ before further processing it. The skin was sectioned vertically and each section was dehydrated and embedded in paraffin wax. The subdivided tissues were stained with hematoxylin and eosin. The sections were observed under microscope and photographed at $40 \times$ magnification. Untreated skin served as control.

Data Analysis The in vitro skin flux was determined from Fick's law of diffusion considering the transport of drugs across the skin barrier as a process of passive diffusion. $\mathrm{J}_{\mathrm{SS}}$, the skin flux $\left(\mu \mathrm{g} / \mathrm{cm}^{2} / \mathrm{h}\right)$, was determined from the slope of the linear portion of the cumulative amount permeated per unit area versus time plot. The lag time $\left(\mathrm{T}_{\mathrm{lag}}, \mathrm{h}\right)$ was determined by extrapolating the linear portion of the curve to the abscissa. Enhancement ratio (ER) was calculated from the following equation:

$\mathrm{ER}=\mathrm{J}_{\mathrm{ss}}$ of test gel $/ \mathrm{J}_{\mathrm{ss}}$ of control gel

Statistical Analysis The results were analyzed 
by paired, two tailed Student's $t$-test using Statistica for Windows (Version 5.0) from StatSoft, Inc., USA. The results were evaluated at probability level of 0.05 . The results are reported as mean \pm SD.

\section{RESULTS AND DISCUSSION}

\section{Effect of Permeation Enhancers Effect of vari-} ous chemical permeation enhancers on the permeation of ketorolac from transdermal formulations across rat abdominal skin was investigated. The enhancers evaluated were DMSO, eucalyptus oil, dlimonene and transcutol. The effectiveness of the enhancer was determined by comparing the steady state flux of ketorolac from chemical enhancer containing gel system and that of control gel system. In vitro permeation profile is presented in Fig. 2 and the permeation parameters obtained after data analysis are reported in Table 1. Among the penetration enhancers evaluated the following order was observed; eucalyptus oil $>$ transcutol $>$ DMSO $>$ d-limonene.

DMSO demonstrated a flux of $27.97 \mu \mathrm{g} / \mathrm{cm}^{2} / \mathrm{h}$ and a $\mathrm{T}_{\text {lag }}$ of $1.97 \mathrm{~h}$. There was an enhancement of 1.55 times. Being a powerful solvent DMSO can mix isothermally with water, it can displace water from the lipid head groups creating gaps around these head groups. DMSO is also capable of displacing water bound to protein head groups. Moreover due to its solvent power, high levels of sulfoxide within the membrane can improve drug partitioning and thus increase the flux. ${ }^{12)}$

Transcutol showed a flux of $29.72 \mu \mathrm{g} / \mathrm{cm}^{2} / \mathrm{h}$ and $\mathrm{T}_{\text {lag }}$ of $2.05 \mathrm{~h}$ with ER of 1.65. Recent studies have shown that transcutol significantly increases the per- cutaneous penetration of various active substances, particularly when used in combination with suitable cosolvents. ${ }^{13-17)}$ Transcutol demonstrated enhanced flux in comparison to DMSO but failed to reduce the lag time. This probably could be due to enhanced accumulation of ketorolac in skin. This enhancer has also shown skin accumulation of topically applied compounds without an increase in transdermal permeation. ${ }^{18)}$

Essential oils like eucalyptus oil are reported to be effective penetration enhancers for 5 -flouorouracil traversing in human skin in vivo with maximum enhancement ratio of 34-fold. ${ }^{19)}$ The principal terpene element within eucalyptus oil is 1 , 8 -cineole, a cyclic

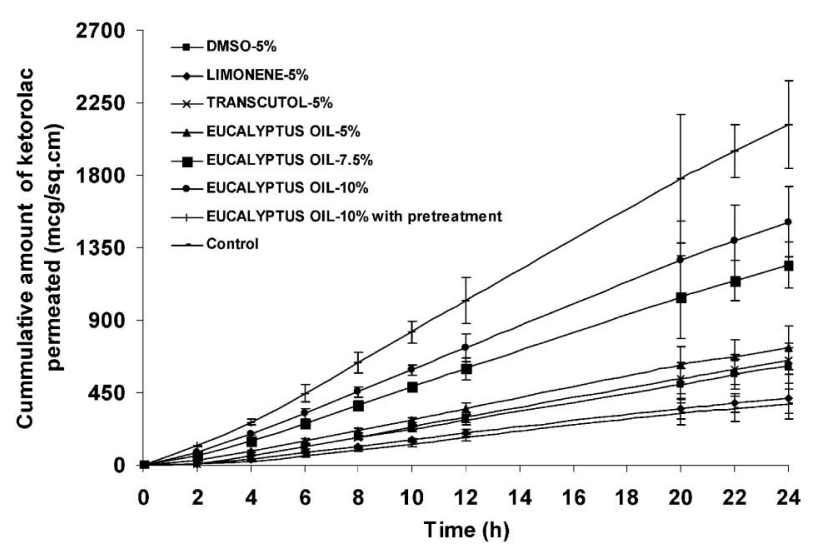

Fig. 2. In Vitro Permeation Profile of Ketorolac through Rat Abdominal Skin from Ketorolac Transdermal Gel System Containing Ketorolac $(2 \%$ w/w), HPMC (2\% w/w), IPA $(25 \% \mathrm{w} / \mathrm{w})$ and Different Enhancers Formulated Using PBS Solution of $\mathrm{pH} 5.4$

Standard deviation values are shown for each data point $(n=4)$ on the graph.

Table 1. Permeation Parameters of Ketorolac through Rat Abdominal Skin from Gel System Containing Ketorolac $(2 \%$ w/w) , HPMC $(2 \%$ w/w), IPA $(25 \%$ w/w) Formulated Using PBS Solution of pH 5.4 along with the Chemical Enhancers at Mentioned Concentration $(n=4)$

\begin{tabular}{lccc}
\hline \hline \multicolumn{1}{c}{ Permeation enhancers } & $\mathrm{ER}^{a}$ & $\begin{array}{c}\mathrm{T}_{\mathrm{lag}}{ }^{b}(\mathrm{~h}) \\
\mathrm{Mean} \pm \mathrm{SD}(n=4)\end{array}$ & $\begin{array}{c}\mathrm{J}_{\mathrm{ss}}{ }^{c}\left(\mu \mathrm{g} / \mathrm{cm}^{2} / \mathrm{h}\right) \\
\operatorname{Mean} \pm \operatorname{SD}(n=4)\end{array}$ \\
\hline Control & 1.00 & $2.71 \pm 0.13$ & $18.04 \pm 0.17$ \\
d-limonene $(5 \% \mathrm{w} / \mathrm{w})$ & 1.05 & $1.67 \pm 0.55$ & $18.89 \pm 0.62$ \\
DMSO $(5 \% \mathrm{w} / \mathrm{w})$ & 1.55 & $1.97 \pm 0.60$ & $27.97 \pm 0.99$ \\
Transcutol $(5 \% \mathrm{w} / \mathrm{w})$ & 1.65 & $2.05 \pm 0.30$ & $29.72 \pm 1.63$ \\
Eucalyptus oil $(5 \% \mathrm{w} / \mathrm{w})$ & 1.80 & $1.34 \pm 0.10$ & $32.47 \pm 0.83$ \\
Eucalyptus oil $(7.5 \% \mathrm{w} / \mathrm{w})$ & 3.04 & $1.14 \pm 0.34$ & $54.79 \pm 3.17$ \\
Eucalyptus oil $(10 \% \mathrm{w} / \mathrm{w})$ & 3.68 & $1.08 \pm 0.32$ & $66.38 \pm 3.12$ \\
Eucalyptus oil $(10 \% \mathrm{w} / \mathrm{w})$ & 5.16 & $1.09 \pm 0.40$ & $93.10 \pm 3.07$ \\
after pretreatment & & & \\
\hline
\end{tabular}

${ }^{a}$ ER: Enhancement ratio, ${ }^{b} \mathrm{~T}_{\text {lag: }}$ lag time, ${ }^{c} \mathrm{~J}_{\mathrm{ss}}$ : skin permeation rate (flux). 
ethers, and proven enhancer ${ }^{20)}$ but its efficacy as an enhancer are mixed. Eucalyptus oil could not enhance the permeation of lipophilic drug like estradiol. Similar results were also reported for the permeation of indomethacin, a lipophilic molecule. The study revealed that oxygen containing terpenes (carvone, 1, 8-cineole) were ineffective ${ }^{21)}$ whereas hydrocarbon terpenes, especially limonene, were effective towards lipophilic drugs. The results of permeation enhancement of ketorolac, a hydrophilic drug also support the above observations towards which oil containing oxygen containing terpenes were effective. The permeation of penetration enhancer itself from the formulation is essential in order to achieve enhanced permeation of drug. The enhancer being lipophilic is believed to readily permeate out of gel into the skin. Eucalyptus oil at $5 \%$ produced a flux of $32.47 \mu \mathrm{g} / \mathrm{cm}^{2} / \mathrm{h}$, an enhancement of 1.80 and a $\mathrm{T}_{\text {lag }}$ of $1.34 \mathrm{~h}$. eucalyptus oil demonstrated maximum permeation rate shortest $\mathrm{T}_{\text {lag. }}$. It was therefore appropriate to study the effect of eucalyptus oil concentration on permeation rate of ketorolac. Increasing the concentration of eucalyptus oil to $7.5 \%$ and $10 \%$ concentration produced a flux of 54.79 and $66.38 \mu \mathrm{g} / \mathrm{cm}^{2} / \mathrm{h}$, an enhancement of 3.04 and 3.68 times and reduction of $\mathrm{T}_{\text {lag }}$ to 1.14 and 1.08 $\mathrm{h}$ respectively. Further increase in eucalyptus oil concentration was not justified due to skin irritation potential of the oil on prolonged contact with the skin.

These essential oils probably modify the solvent nature of the stratum corneum, improving drug partitioning into the tissue. Terpenes are generally good solvents and permeate skin well, ${ }^{22)}$ with loss of terpenes, from a formulation there could be an alteration of the thermodynamic activity of the permeant. Terpenes may also modify drug diffusivity through the membrane and bring about a reduction of the lag time for permeation, indicating increase in diffusivity of the drug through the membrane following terpene treatment. X-ray diffraction studies have also indicated that d-limonene and 1,8-cineole disrupt stratum corneum bilayer lipids. ${ }^{23)}$

Effect of Pretreatment with Abrading Gel Attempts were made to enhance the permeation of ketorolac across skin by abrading the upper skin layer with the help of abrading gel made of crushed apricot seed. There was 5.16 times enhancement in permeation of ketorolac across rat skin from formulation containing ketorolac $(2 \% \mathrm{w} / \mathrm{w}), \operatorname{HPMC}(2 \% \mathrm{w} / \mathrm{w})$,
IPA $(25 \% \mathrm{w} / \mathrm{w})$ and eucalyptus oil $(10 \% \mathrm{w} / \mathrm{w})$ prepared in PBS solution of $\mathrm{pH}$ 5.4. The $\mathrm{J}_{\mathrm{ss}}$ and $\mathrm{T}_{\mathrm{lag}}$ of $93.10 \mu \mathrm{g} / \mathrm{cm}^{2} / \mathrm{h}$ and $1.09 \mathrm{~h}$ were attained respectively after pretreatment.

Skin Irritation Studies The results of the skin irritation studies based on visual observation score suggest that the formulations were safe to be applied on skin. The scores for d-limonene and Transcutol were between $0-1$; while that for eucalyptus oil and DMSO were between $0-2$.

Histological Studies The control skin (Fig. 3A) showed intact stratum corneum with no swelling of epidermis. No inflammatory cells were seen. The normal skin stratification was intact. Various chemical enhancers dramatically affected the skin. Transdermal formulation containing d-limonene fluidized the inner lipid layers and mild increase in the number of inflammatory cells was observed but the stratum corneum was found to be almost intact (Fig. 3B). Formulation containing DMSO demonstrated significant fluidization of the inner dermis; the stratum corneum was seen disrupted though inflammatory cells were not observed (Fig. 3C). Transdermal formulation containing eucalyptus oil fluidized the inner dermal lipids; the skin was found swollen with slight increase in the number of inflammatory cells (Fig. 3D). On treatment of skin with formulation containing transcutol it was observed that only the epidermal portion had swollen with slight fluidization in this part while the basic stratification of the skin was almost maintained (Fig. 3E). The effect of abrading the skin with abrading gel followed by treatment with transdermal formulation containing eucalyptus oil was observed on the skin. Stratum corneum was disrupted the skin lipids were vastly fluidized and the skin appeared swollen (Fig. 3F).

Anti-inflammatory Response The formulation showed a prominent increase in activity in the carrageenan induced paw inflammation model. Fig. 4 represents the anti inflammatory activity after oral administration and after transdermal application after treatment with abrading gel.

Ketorolac transdermal patch formulation demonstrated comparable anti-inflammatory potential to orally administered ketorolac. The anti-inflammatory potential was measured in terms of the AUC of graph plotted between difference in paw diameter and time. Compared to the \% AUC for untreated paw which was taken as $100 \%$, oral administration showed swell- 

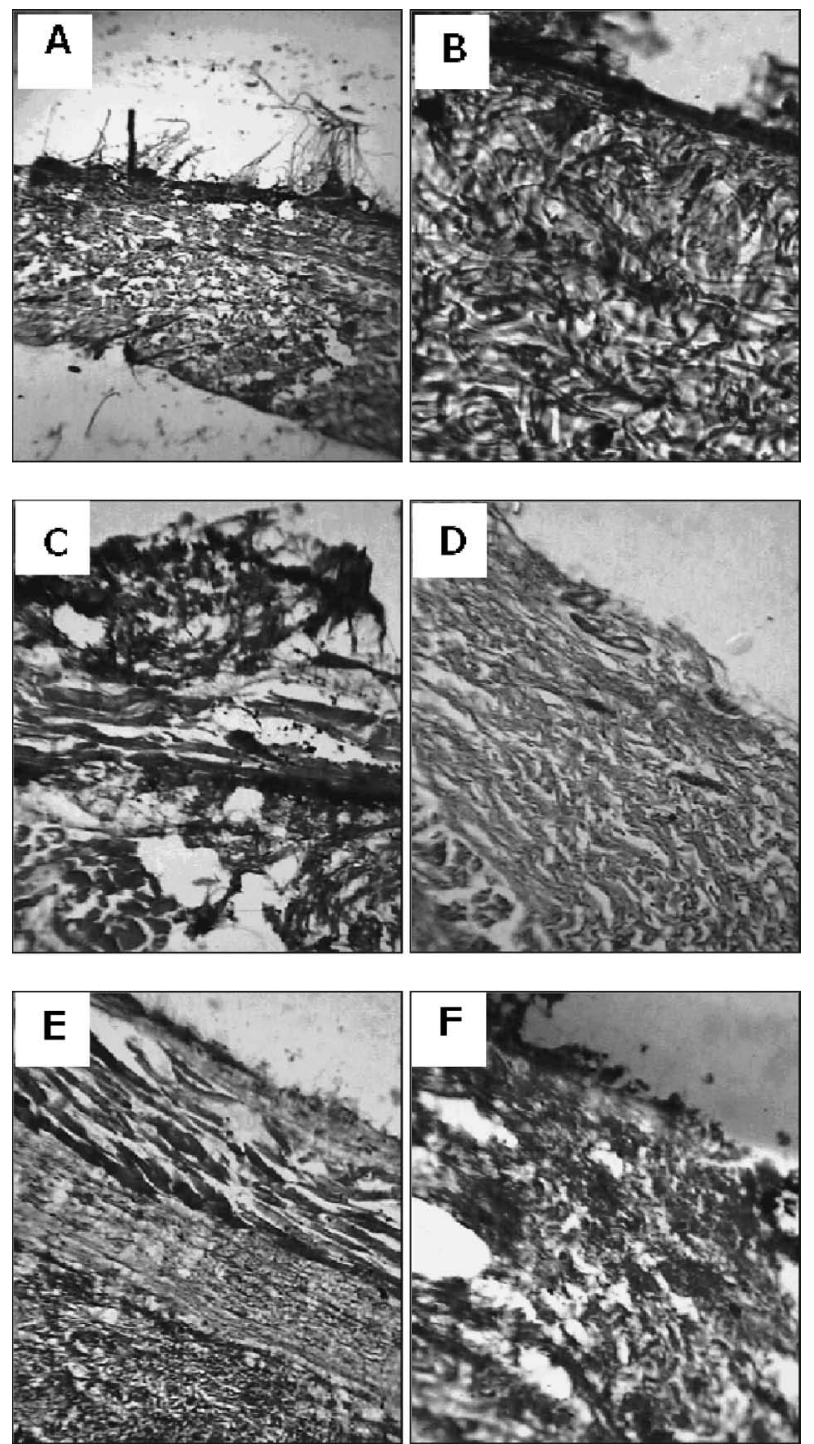

Fig. 3. Histological Findings after Treatment of Rat Abdominal Skin for $24 \mathrm{~h}$ with Chemical Permeation Enhancer Gel System Observed under Microscope after Staining with Hematoxylin-eosin Stain

A-Control $(10 \times)$, B-d-limonene $(40 \times)$, C-DMSO $(40 \times)$, D-Eucalyptus oil $(40 \times)$, E-Transcutol $(40 \times)$ and F-Application of eucalyptus oil preparation after pretreatment $(40 \times)$.

ing of $64.04 \%$ while transdermal application after pretreatment demonstrated swelling of $60.67 \%$. Maximum percentage inhibition was observed at $6 \mathrm{~h}$ and 4 $\mathrm{h}$ for oral and transdermal application after pretreatment of $50 \%$ and $45.45 \%$ respectively. There is clear evidence of enhanced permeation with quicker onset of action for the transdermal formulation applied after pretreatment. Abrasion of skin by crushed seeds of apricot probably helps in removing if not completely at least partially the upper stratum corneum thus aiding permeation enhancement.

Antinociceptive Response There was $88.10 \%$

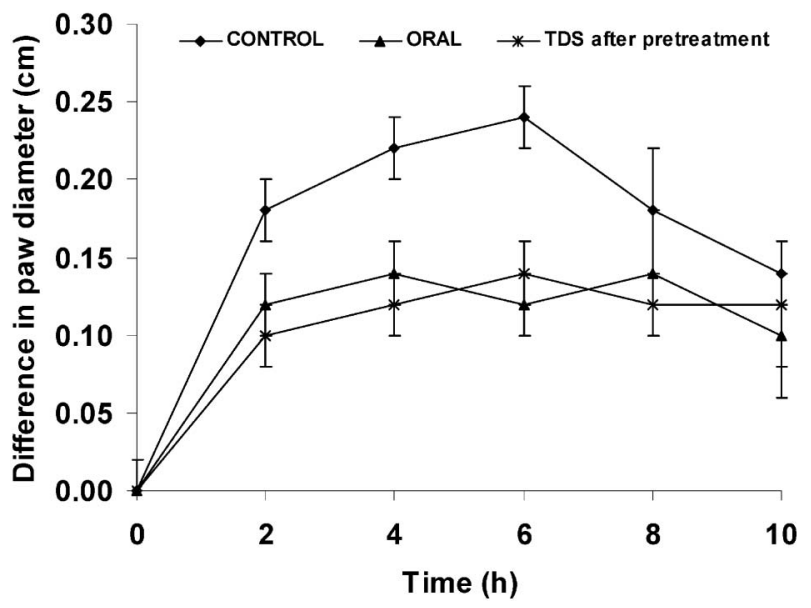

Fig. 4. Anti-inflammatory Activity of Ketorolac on Paw Edema Induced with Carrageenan Injection $(0.05 \mathrm{ml}$ of $0.5 \% \mathrm{w} /$ w) in Rats (Control) and after Oral Administration of Ketorolac Solution $(2 \mathrm{mg} / \mathrm{kg}$ ) (Oral) and on Application of Transdermal Patch of Ketorolac (TDS) after Pretreatment with Abrading Gel

The reservoir transdermal patch formulation contained ketorolac ( $2 \%$ w/w), HPMC ( $2 \%$ w/w), IPA $(25 \%$ w/w) and eucalyptus oil $(10 \% \mathrm{w} / \mathrm{w})$ formulated using PBS solution of pH 5.4 in the reservoir chamber. Standard deviation values are shown for each data point $(n=4)$ on the graph.

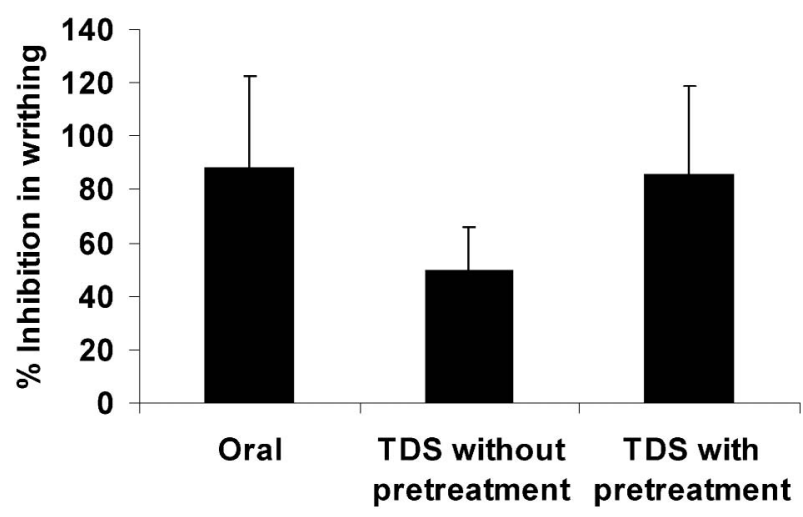

Fig. 5. Antinociceptive Response of Ketorolac $15 \mathrm{~min}$ after Induction of Writhes with the Help of Acetic Acid $(20 \mathrm{mg}$ / $\mathrm{kg} ; 2 \mathrm{ml} / \mathrm{kg}$ ) after Oral Administration of Ketorolac (2 mg/ $\mathrm{kg}$ ) and on Application of Transdermal Patch of Ketorolac (TDS) without Pretreatment and after Pretreatment with Abrasive Gel Preparation

The transdermal patch formulation contained ketorolac $(2 \% \mathrm{w} / \mathrm{w})$, HPMC $(2 \% \mathrm{w} / \mathrm{w})$, IPA $(25 \% \mathrm{w} / \mathrm{w})$ and eucalyptus oil $(10 \% \mathrm{w} / \mathrm{w})$ formulated using PBS solution of pH 5.4 in the reservoir chamber. Standard deviation values are shown for each data point $(n=4)$ on the graph.

inhibition in writhing on oral administration was observed while application of transdermal application without pretreatment and after pretreatment demonstrated $50 \%$ and $85.71 \%$ inhibition in writhing response (Fig. 5). The acetic acid induced writhing response is a sensitive procedure to evaluate peripherally acting analgesics. The response is thought to be 
mediated by peritoneal mast cells, ${ }^{24)}$ acid sensing ion channels ${ }^{25)}$ and the prostaglandin pathways. ${ }^{26)}$ The reservoir type transdermal patch consisting of ketorolac gel thus appears promising in delivering the drug across skin.

\section{REFERENCES}

1) Buckley M., Brogden R., Drug, 39, 86-109 (1990).

2) Rooks W., Maloney P., Shott L., Schuler M., Sevelius H., Strosberg A., Tanenbaum L., Tomolonis A., Wallach M., Waterbury D., Yee J., Drugs Exp. Clin. Res., 11, 479-492 (1985).

3) Tiwari S. B., Udupa N., Int. J. Pharm., 260, 93-103 (2003).

4) Roy S. D., Manoukian E., Combs D., J. Pharm. Sci., 84, 49-52 (1995).

5) Cho Y. A., Gwak H. S., Drug Dev. Ind. Pharm., 30, 557-564 (2004).

6) Tiwari S. B., Pai R. M., Udupa N., Drug Deliv., 11, 47-51 (2004).

7) Chavez R., Bravo C., Zazueta C., Pichardo J., Uribe A., Corona N., Reyes-Vivas H., Gonzalez C., Chavez E., J. Pharmacol. Exp. Ther., 267, 1134-1139 (1993).

8) Kim B., Doh H., Le T. N., Cho W., Yong C., Choi H., Kim J. S., Lee C., Kim D., Int. J. Pharm., 293, 193-202 (2005).

9) Doh, H., Cho, W., Yong, C., Choi, H., Kim J. S., Lee C., Kim D., J. Pharm. Sci., 92, 1008-1017 (2003).

10) Draize, J. H., Dermal Toxicity in Appraisal of the Safety of Chemicals in Foods, Drugs and Cosmetics. The Association of Food and Drug Officials of the United States, Bureau of Food and Drugs, Austin Texas, 1959, pp. 46-59.

11) Alol A., Kuriyama K., Shimizu T., Yoshioka M., Int. J. Pharm., 93, 1-6 (1993) .

12) Williams A. C., Barry B. W., Int. J. Pharm., 74, 157-168 (1991).

13) Barry, B. W., J. Contr. Rel., 6, 85-97 (1987).

14) Ganem A.-Q., Lafforgue A. C., Falson-Rieg B. P., Int. J. Pharm., 147, 165-172 (1997).

15) Lee T. W., Kim J. C., Hwangl S. J., Eur. J. Pharm. Biopharm., 56, 407-412 (2003).

16) Mura P., Faucci M. T., Bramanti G., Corti P., Eur. J. Pharm. Sci., 9, 365-372 (2000) .

17) Touitou E., Levy F.-S., Dayan N., Alhaique F., Riccieri F., Int. J. Pharm., 103, 131-136 (1994).

18) Watkinson A. C., Hadgraft J., Bye A., Int. J. Pharm., 74, 229-236 (1991).

19) Godwin D. A., Kim N. H., Felton L. A., Eur. J. Pharm. Biopharm., 53, 23-27 (2002) .

20) Williams A. C., Barry B. W., Int. J. Pharm., 57, R7-R9 (1989).

21) Okabe H., Takayama K., Ogura A., Nagai T., Drug Des. Deliv., 4, 313-321 (1989).

22) Cornwell P. A., Barry B. W., J. Pharm. Pharmacol., 46, 261-269 (1994).

23) Cornwell P. A., Barry B. W., Bouwstra J. A., Gooris G. S., Int. J. Pharm, 27, 9-26 (1996).

24) Ronaldo A., Mariana L., Sara M., Adriana B., Steve P., Ferreira S., Fernando Q., Eur. J. Pharmacol., 387, 111-118 (2000).

25) Voilley N., Current Drug Targets - Inflammation, Allergy, 3, 71-79 (2004).

26) Vogel H., Vogel W., Pharmacological Assays. In: Drug Discovery and Evaluation: Springer Verlag, Germany, 1997, pp. 368-370. 